\title{
Association between vitamin $D$ level at birth and respiratory morbidities in very-low-birth-weight infants
}

lan Kim, MD', Sung Shin Kim, MD, PhD', Jee In Song, MD', Seock Hwa Yoon, MD', Ga Young Park, MD, PhD', Yong-Wha Lee, MD, PhD ${ }^{2}$

Departments of ${ }^{1}$ Pediatrics and ${ }^{2}$ Laboratory Medicine, Soonchunhyang University Bucheon Hospital, Soonchunhyang University College of Medicine, Bucheon, Korea

Purpose: This study aimed to evaluate vitamin D status at birth in very-low-birth-weight infants (VLBWIs: $<1,500 \mathrm{~g}$ ) and to determine the association between vitamin $\mathrm{D}$ level and respiratory morbidity. Methods: A retrospective study was conducted at Soonchunhyang University Bucheon Hospital between November 2013 and November 2017. We collected blood samples and data on respiratory morbidity from 230 VLBWIs on the first day of life. Patients who were transferred to other hospitals $(n=19)$, died before 36 weeks of gestational age $(n=18)$, or whose blood samples were not collected immediately after birth $(n=5)$ were excluded. Finally, 188 patients were enrolled. VLBWIs with different vitamin D levels were compared with respect to demographic features, maternal diseases, respiratory morbidities, and other neonatal diseases.

Results: The mean serum vitamin D level, as measured by 25 -hydroxyvitamin D (25(OH)D), was $13.4 \pm$ $9.3 \mathrm{ng} / \mathrm{mL}$. The incidence of vitamin D deficiency $(<20 \mathrm{ng} / \mathrm{mL})$ was $79.8 \%$, and $44.1 \%$ of preterm infants had severe vitamin $D$ deficiency $(<10 \mathrm{ng} / \mathrm{mL}$ ). Logistic analysis shows that a low serum $25(\mathrm{OH}) \mathrm{D}$ level $(<20 \mathrm{ng} / \mathrm{mL}$ ) was a risk factor for respiratory distress syndrome (odds ratio [OR], 4.32; $P=0.010$ ) and bronchopulmonary dysplasia $(\mathrm{OR}, 4.11 ; P=0.035)$.

Conclusion: The results showed that $79.8 \%$ of preterm infants in this study had vitamin $\mathrm{D}$ deficiency at birth. Low vitamin $\mathrm{D}$ status was associated with respiratory morbidity, but the exact mechanism was unknown. Additional studies on the association between vitamin D level and neonatal morbidity are required.

Key words: Very low birth weight infants, Vitamin D deficiency, Newborn respiratory distress syndrome, Bronchopulmonary dysplasia

\section{Introduction}

Vitamin D is a fat-soluble vitamin that plays a major role in calcium and phosphorus homeostasis and bone metabolism in the body. It is involved in innate and acquired immune responses and autoimmune responses, and it inhibits cancer cell proliferation, regulates cardiovascular function, and regulates hormones such as insulin."

The fetus itself does not produce vitamin $\mathrm{D}$, but receives vitamin $\mathrm{D}$ from the mother. A verylow-birth-weight infant (VLBWI; birth weight $<1,500$ g) has a short gestational age, resulting in reduced vitamin $\mathrm{D}$ received from the mother, poor nutritional support, and poor exposure to sunlight during neonatal intensive care unit (NICU) hospitalization.

Therefore, vitamin D deficiency is common and increases the likelihood of neonatal morbidities and death. ${ }^{2-4)}$ The relationship between vitamin D deficiency and preterm infant diseases such as sepsis, ${ }^{5,6}$ necrotizing enterocolitis (NEC), ${ }^{7}$ respiratory distress syndrome (RDS), ${ }^{8)}$ and bronchopulmonary dysplasia (BPD) ${ }^{9,10}$ is under investigation.
Corresponding author: Sung Shin Kim, MD, PhD Department of Pediatrics, Soonchunhyang University Bucheon Hospital, Soonchunhyang University College of Medicine, 170 Jomaru-ro, Bucheon 14584, Korea

Tel: +82-32-621-5420

Fax: +82-32-621-5662

E-mail: sungshin1201@gmail.com https://orcid.org/0000-0001-9724-3006

Received: 7 May, 2018

Revised: 28 September, 2018

Accepted: 15 October, 2018
Copyright (C 2019 by The Korean Pediatric Society

This is an open-access article distributed under the terms of the Creative Commons Attribution NonCommercial License (http://creativecommons.org/ licenses/by-nc/4.0/ which permits unrestricted noncommercial use, distribution, and reproduction in any medium, provided the original work is properly cited. 
RDS is diagnosed in 50\% of VLBWIs and is a common cause of premature infant death. ${ }^{11)}$ BPD accounts for 23\% of VLBWIs and $52 \%$ of preterm infants 501 to $750 \mathrm{~g} .^{.2)}$

According to Nguyen et al. ${ }^{13)}$, vitamin D plays a role in the interactions between mesenchymal cells and alveolar epithelial cells and is involved in the maturation of the fetal lung. Type II alveolar cells express vitamin D receptor and are involved in the synthesis and secretion of surfactants in response to vitamin D. The role of vitamin D in pulmonary development and maturation and postnatal respiratory diseases has been researched as a new field of study. However, to best of our knowledge, no study has reported the association between vitamin D level and preterm morbidities in VLBWIs in Korea. In this study, we reviewed the clinical outcomes at NICUs and the incidence of respiratory diseases as it relates to vitamin D levels immediately after birth.

\section{Materials and methods}

We retrospectively reviewed the medical records of VLBWIs who were admitted to the NICU between November 2013 and November 2017 at Soonchunhyang University Bucheon Hospital (latitude $37.5^{\circ} \mathrm{N}$ ). Infants who were transferred to another hospital ( $n=19$; mean duration of hospitalization was 36.1 \pm 28.9 days; range, 3-96 days) or whose blood was not sampled $(n=5)$ were excluded. Infants who died before 36 weeks of gestational age $(n=18)$ were also excluded to satisfy the diagnostic criteria of BPD. Fig. 1 shows a flowchart of the study course.

Finally, 188 patients were enrolled in the study, and vitamin D was measured within 24 hours of birth. The clinical parameters were birth weight, gestational age, sex, mode of delivery, Apgar score (1and 5-min), twin birth, birth season, hospitalization period, death, and oxygen therapy method and duration.

The seasons were defined as spring (March to May), summer (June to August), autumn (September to November), and winter (December to February). Premature infant diseases include RDS, BPD, pneumothorax, pulmonary hemorrhage, sepsis, NEC, retinopathy of prematurity (ROP), patent ductus arteriosus (PDA), periventricular leukomalacia (PVL), and intraventricular hemorrhage (IVH). Maternal illnesses that were shown to be associated with vitamin D

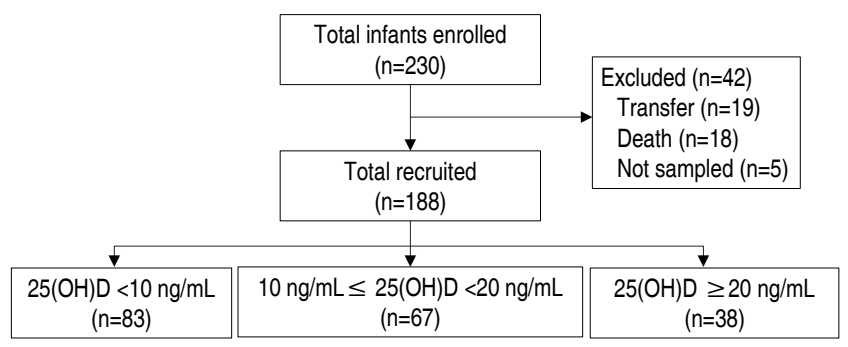

Fig. 1. Flow of study participants. 25(OH)D, 25-hydroxyvitamin D. deficiency, such as gestational diabetes mellitus (DM), premature rupture of membranes (PROM), and preeclampsia, were estimated. ${ }^{14,15)}$

The Institutional Review Board of Soonchunhyang University Bucheon Hospital approved the medical record review for this study and exemption from patient consent (approval number: 2017-08014).

\section{Definitions of morbidities and serum measurements of vitamin D}

RDS was diagnosed based on clinical symptoms, chest X-ray, and blood gas analysis. BPD was diagnosed on the basis of radiographic findings and the need for and methods of $\mathrm{O}_{2}$ therapy after 28 days of age.

We decided to divide $\mathrm{O}_{2}$ therapy into invasive methods and noninvasive methods. Ventilator application was defined as an invasive method regardless of the ventilator mode. On the other hand, nasal prong, high flow nasal cannula, noninvasive positive pressure ventilation, and nasal continuous positive airway pressure were considered as noninvasive $\mathrm{O}_{2}$ therapy. We documented the respiratory severity score (RSS) in intubated preterm infants ( $\mathrm{RSS}=\mathrm{FiO}_{2} \times$ mean airway pressure) on days 1 and 21.

Sepsis was diagnosed when blood cultures were positive and systemic symptoms appeared.

NEC was diagnosed according to the modified Bell et al.'s staging ${ }^{16)}$ criteria based upon the severity of systemic, intestinal, and radiographic findings. PDA was diagnosed based on clinical symptoms and echocardiography. ROP was diagnosed by an ophthalmologist through retinal examination according to the schedule of the American Academy of Ophthalmology. ${ }^{17)}$

IVH and PVL were diagnosed using brain ultrasound and brain magnetic resonance imaging (MRI). The initial brain ultrasound was performed within 72 hours of birth, and rescreening was performed at intervals of 1 to 4 weeks. In cases of an abnormal brain ultrasound or neurological symptoms, a brain MRI was performed prior to discharge.

Samples were collected from a peripheral vein within 24 hours of life, and vitamin D was measured in 25-hydroxyvitamin D (25(OH) D), the main circulatory form. The 25(OH)D levels were measured by the ultra-performance liquid chromatography-tandem mass spectrometry and chemiluminescence immunoassay method. Alkaline phosphatase (ALP) was measured by a colorimetric method.

According to the Holick et al., ${ }^{18)}$ vitamin $\mathrm{D}$ deficiency is defined as a $25(\mathrm{OH}) \mathrm{D}$ level below $20 \mathrm{ng} / \mathrm{mL}$ ( $50 \mathrm{nmol} / \mathrm{L}$ ), and vitamin $\mathrm{D}$ insufficiency is defined as a $25(\mathrm{OH}) \mathrm{D}$ level of 21-29 ng/mL (52.5$72.5 \mathrm{nmol} / \mathrm{L})$. In this study, subjects were classified into 3 categories: group 1, severe vitamin D deficiency $(25(\mathrm{OH}) \mathrm{D}<10 \mathrm{ng} / \mathrm{mL})$; group 2, deficiency (10-20 ng/mL); group 3, insufficiency (20-30 ng/mL) plus sufficiency ( $\geq 30 \mathrm{ng} / \mathrm{mL}$ ). We analyzed whether the frequencies of variables differed between groups.

Vitamin D was initially administered via M.V.H. (Whanin Pharm 
Co., Ltd., Seoul, Korea). It contains vitamin $\mathrm{D}_{2}$, and the dose was 100 $\mathrm{IU} / \mathrm{kg}$. After the start of enteral feeding, vitamin D was supplemented with breast milk, preterm formula, breast milk fortifier, and vitamin D drops. We used Sunny D Drops (GMP Laboratories of America, Inc., Anaheim, CA, USA), which contain vitamin $\mathrm{D}_{3}$. There were no established standards for supplementation of vitamin $D$ in the early period of this study. After February 2016, we administered $400 \mathrm{IU}$ for vitamin D sufficiency, 1,200 IU for severe deficiency, and 400 to $800 \mathrm{IU}$ for values in between; however, these were not absolute standards.

\section{Statistical analysis}

Data were analyzed using IBM SPSS Statistics ver. 20.0 (IBM Co., Armonk, NY, USA). The qualitative data were presented as numbers and percentages while quantitative data were presented as means and standard deviations. Comparisons of qualitative data between groups were done using the chi-square test and/or Fisher exact test. Comparisons of quantitative data between groups were done using analysis of variance. Logistic regression analysis was used to assess the relationship between 25(OH)D levels and premature infant diseases. A $P$ value of less than 0.05 was considered significant.

\section{Results}

This study enrolled 188 VLBWIs. Patients with vitamin D deficiency accounted for $79.8 \%(n=150)$ of the study population. The number of neonates with severe vitamin D deficiency was 83 (44.1 $\%$ ), and $38(20.2 \%)$ had vitamin D insufficiency or sufficiency.

The patients demographic features are presented in Table 1. Overall, the neonates' mean gestational age was $28.4 \pm 3.0$ weeks of gestation, and their mean birth weight was 1,104.7 $\pm 298.1 \mathrm{~g}$. Male neonates accounted for $52.7 \%$ of the study population, and no significant differences in weight were found between groups according to sex. Serum ALP concentrations were significantly higher in patients with severe vitamin D deficiency.

The average 25(OH)D level in boys $(12.5 \pm 8.5 \mathrm{ng} / \mathrm{mL})$ was lower than that in girls $(14.3 \pm 10.1 \mathrm{ng} / \mathrm{mL})$, but the $P$ value was not signi-

Table 1. Patient demographics

\begin{tabular}{|c|c|c|c|c|c|}
\hline Variable & Total $(n=188)$ & Group $1(n=83)$ & Group $2(n=67)$ & Group $3(n=38)$ & $P$ value \\
\hline $25(\mathrm{OH}) \mathrm{D}(\mathrm{ng} / \mathrm{mL})$ & $13.4 \pm 9.3$ & $5.5 \pm 2.4$ & $14.7 \pm 2.7$ & $28.2 \pm 7.2$ & $<0.001$ \\
\hline ALP (IU/L) & $410.9 \pm 278.5$ & $563.2 \pm 327.4$ & $319.2 \pm 159.1$ & $240.0 \pm 109.4$ & $<0.001$ \\
\hline Gestational age (wk) & $28.4 \pm 3.0$ & $28.3 \pm 3.3$ & $28.5 \pm 3.2$ & $29.1 \pm 2.5$ & 0.15 \\
\hline Birth weight (g) & $1,104.7 \pm 298.1$ & $1,045.2 \pm 293.8$ & $1,098.3 \pm 297.4$ & $1,245.7 \pm 267.1$ & 0.0002 \\
\hline Male sex & $99(52.7)$ & $46(55.4)$ & $38(56.7)$ & $15(39.5)$ & 0.188 \\
\hline Twins & $56(29.8)$ & $29(34.9)$ & $18(26.9)$ & $9(23.7)$ & 0.367 \\
\hline Mode of delivery & & & & & 0.57 \\
\hline Vaginal & $21(11.2)$ & $7(8.4)$ & $9(13.4)$ & $8(21.1)$ & \\
\hline Caesarean section & 167 (88.8) & $76(91.6)$ & $58(86.6)$ & $33(86.8)$ & \\
\hline Apgar score at 1 min & $4.8 \pm 2.1$ & $4.3 \pm 2.0$ & $4.8 \pm 2.1$ & $5.5 \pm 1.7$ & 0.007 \\
\hline Apgar score at 5 min & $7.8 \pm 1.5$ & $7.2 \pm 1.5$ & $7.6 \pm 1.3$ & $7.7 \pm 1.4$ & 0.081 \\
\hline Birth season & & & & & 0.075 \\
\hline Spring & $44(23.4)$ & $26(31.3)$ & $12(17.9)$ & $6(15.8)$ & \\
\hline Summer & $47(25.0)$ & $15(18.1)$ & $20(29.9)$ & $12(31.6)$ & \\
\hline Fall & $39(20.7)$ & $16(19.3)$ & $11(16.4)$ & $12(31.6)$ & \\
\hline Winter & $58(30.9)$ & $26(31.3)$ & $24(35.8)$ & $8(21.1)$ & \\
\hline Maternal age (yr) & $33.2 \pm 4.2$ & $34.2 \pm 4.2$ & $32.5 \pm 4.2$ & $32.2 \pm 3.3$ & 0.031 \\
\hline \multicolumn{6}{|l|}{ Maternal history } \\
\hline Antenatal steroid & $97(51.6)$ & $48(57.8)$ & $29(43.3)$ & $20(52.6)$ & 0.206 \\
\hline PROM & $62(33.0)$ & $28(33.7)$ & $19(28.4)$ & $15(39.5)$ & 0.498 \\
\hline Preeclampsia & $41(21.8)$ & $20(24.1)$ & $14(20.9)$ & $7(18.4)$ & 0.762 \\
\hline DM & $21(11.2)$ & $12(14.5)$ & $5(7.5)$ & $4(10.5)$ & 0.397 \\
\hline Vitamin D supplementation & $576.6 \pm 281.9$ & $727.7 \pm 331.4$ & $486.6 \pm 164.1$ & $405.3 \pm 118.4$ & $<0.001$ \\
\hline
\end{tabular}

Values are presented as mean \pm standard deviation or number (\%).

$P$ values were calculated by analysis of variance for continuous variables and chi-square test (or Fisher exact test) for categorical variables.

Group 1, 25(OH)D of neonates $<10 \mathrm{ng} / \mathrm{mL}$; group 2, 25(OH)D of neonates=10 to $20 \mathrm{ng} / \mathrm{mL}$; group 3, 25(OH)D of neonates $\geq 20 \mathrm{ng} / \mathrm{mL}$.

25(OH)D, 25-hydroxyvitamin D; ALP, alkaline phosphatase; PROM, premature rupture of membrane; DM, diabetes mellitus.

Boldface indicates a statistically significant difference with $P<0.05$. 
ficant $(P=0.2)$. One hundred thirty-two infants $(70.2 \%)$ were singleton births, and 56 (29.8\%) were twin births. The birth weight of group 1 was $1,045.2 \pm 293.8 \mathrm{~g}$, while that of group 3 was $1,245.7 \pm 267.1$ $\mathrm{g}$. There was no difference between groups with respect to birth season $(P=0.075)$. However, when we compared vitamin $\mathrm{D}$ levels by birth season, the mean value of vitamin $D$ was $10.4 \pm 7.7 \mathrm{ng} / \mathrm{mL}$ in spring, $15.7 \pm 9.5 \mathrm{ng} / \mathrm{mL}$ in summer, $16.2 \pm 10.9 \mathrm{ng} / \mathrm{mL}$ in autumn, and $12.0 \pm 8.6 \mathrm{ng} / \mathrm{mL}$ in winter, which were statistically significant $(P=$ 0.007). There were significant differences in birth weight $(P<0.001)$, Apgar score at 1 minute $(P=0.007)$, and maternal age $(P=0.031)$.

The mean maternal age was $33.2 \pm 4.2$ years. The frequency of maternal disease (PROM, DM, preeclampsia) was not significantly different depending on the vitamin $\mathrm{D}$ level.

The clinical outcomes are shown in Table 2. The average duration of hospitalization was 65.1 \pm 51.3 days for group 1, 49.8 28.1 days for group 2, and $42.3 \pm 18.1$ days for group 3. This difference was statistically significant $(P=0.005)$. The total number of deaths was 6 , with no significant difference between groups. In the oxygen therapy period, the total $\mathrm{O}_{2}$ usage period, the mechanical ventilation period, and the noninvasive $\mathrm{O}_{2}$ usage period were all significantly higher in group 1 than in the other groups $(P<0.001)$.

RSS on days 1 and 21 were both higher in the group with lower vitamin D levels, and this difference was statistically significant. Pearson correlation demonstrated a negative correlation between vitamin D levels and RSS on day $1(P<0.001, r=-0.38)$, as seen in Fig. 2.

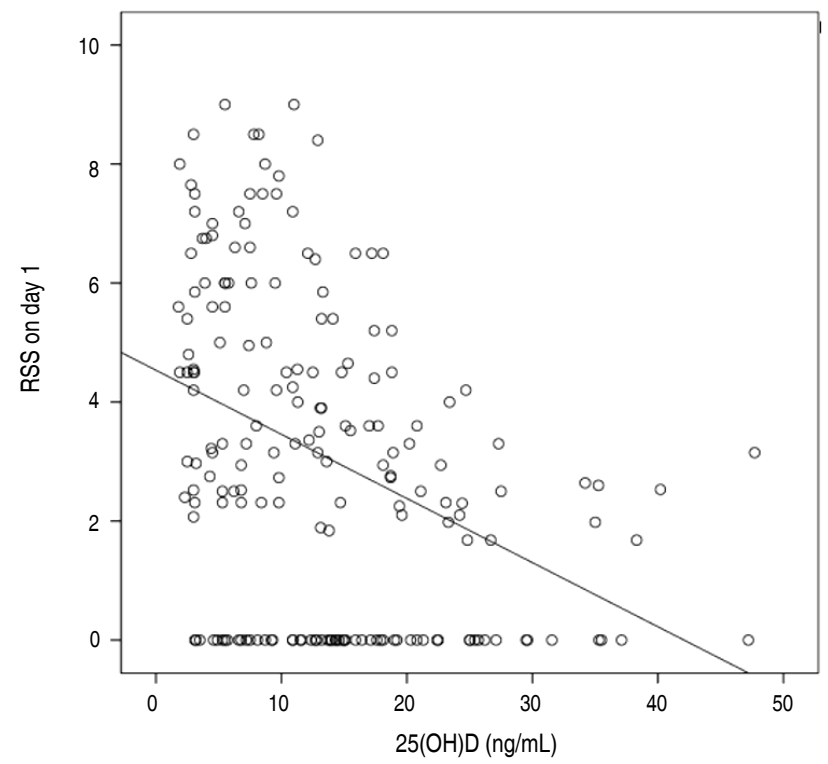

Fig. 2. Pearson correlation between $25(\mathrm{OH}) \mathrm{D}$ and respiratory severity score (RSS) on day 1. 25(OH)D, 25-hydroxyvitamin D.

Table 2. Clinical outcomes in preterm infants

\begin{tabular}{|c|c|c|c|c|c|}
\hline Variable & $\begin{array}{c}\text { Total } \\
(n=188)\end{array}$ & $\begin{array}{c}25(\mathrm{OH}) \mathrm{D}<10 \mathrm{ng} / \mathrm{mL} \\
(\mathrm{n}=83)\end{array}$ & $\begin{array}{c}25(\mathrm{OH}) \mathrm{D}, 10-30 \mathrm{ng} / \mathrm{mL} \\
(\mathrm{n}=67)\end{array}$ & $\begin{array}{c}25(\mathrm{OH}) \mathrm{D}>20 \mathrm{ng} / \mathrm{mL} \\
(\mathrm{n}=38)\end{array}$ & $P$ value \\
\hline Hospitalization period (day) & $55.1 \pm 39.8$ & $65.1 \pm 51.3$ & $49.8 \pm 28.1$ & $42.3 \pm 18.1$ & 0.005 \\
\hline Death before discharge & $18(9.6)$ & $6(7.2)$ & $6(9.0)$ & $6(15.8)$ & 0.324 \\
\hline \multicolumn{6}{|l|}{$\mathrm{O}_{2}$ supplement } \\
\hline Duration of total $\mathrm{O}_{2}$ usage (day) & $20.9 \pm 28.2$ & $31.8 \pm 36.4$ & $14.5 \pm 16.5$ & $8.2 \pm 9.7$ & $<0.001$ \\
\hline Duration of mechanical ventilation (day) & $7.6 \pm 14.1$ & $12.6 \pm 18.7$ & $5.1 \pm 8.3$ & $1.1 \pm 1.8$ & $<0.001$ \\
\hline Duration of noninvasive $\mathrm{O}_{2}$ usage (day) & $13.4 \pm 17.6$ & $19.6 \pm 22.5$ & $9.3 \pm 10.5$ & $7.1 \pm 9.5$ & $<0.001$ \\
\hline Surfactant $\geq 1$ dose & $135(71.8)$ & $67(80.7)$ & $48(71.6)$ & $20(52.6)$ & 0.006 \\
\hline RSS on day 1 & $2.7 \pm 2.6$ & $4.1 \pm 2.7$ & $2.8 \pm 2.5$ & $1.39 \pm 1.4$ & $<0.001$ \\
\hline RSS on day 21 & $0.2 \pm 0.8$ & $0.7 \pm 1.4$ & $0.3 \pm 1.0$ & - & 0.005 \\
\hline \multicolumn{6}{|l|}{ Neonatal diseases } \\
\hline RDS & $133(70.7)$ & $72(86.7)$ & $45(67.2)$ & $16(42.1)$ & $<0.001$ \\
\hline $\mathrm{BPD}$ & 55 (29.3) & $38(45.8)$ & 14 (20.9) & $3(7.9)$ & $<0.001$ \\
\hline Pneumothorax & $10(5.3)$ & $8(9.6)$ & $2(3.0)$ & $0(0.0)$ & 0.051 \\
\hline Pulmonary hemorrhage & $11(5.9)$ & $7(8.4)$ & $2(3.0)$ & $2(5.3)$ & 0.363 \\
\hline PDA & $91(48.4)$ & $44(53.0)$ & 29 (43.3) & $18(47.4)$ & 0.490 \\
\hline ROP & 40 (21.3) & 27 (32.5) & $11(16.4)$ & $2(5.3)$ & 0.001 \\
\hline NEC & $39(20.7)$ & $17(20.5)$ & $17(25.4)$ & $5(13.2)$ & 0.141 \\
\hline Sepsis & $29(15.4)$ & $17(20.5)$ & $9(13.4)$ & $3(7.9)$ & 0.175 \\
\hline PVL & $3(1.6)$ & $2(2.4)$ & $1(1.5)$ & $0(0)$ & 1.000 \\
\hline IVH (grade III and IV) & 34 (18.1) & $6(7.2)$ & $4(6.0)$ & $2(5.3)$ & 1.000 \\
\hline
\end{tabular}

Values are presented as mean \pm standard deviation or number (\%).

$P$ values were calculated by analysis of variance for continuous variables and chi-square test (or Fisher exact test) for categorical variables.

25(OH)D, 25-hydroxyvitamin D; RSS, respiratory severity score; RDS, respiratory distress syndrome; BPD, bronchopulmonary dysplasia; PDA, patent ductus arteriosus; ROP, retinopathy of prematurity; NEC, necrotizing enterocolitis; PVL, periventricular leukomalacia; IVH, intraventricular hemorrhage.

Boldface indicates a statistically significant difference with $P<0.05$. 
Table 3. Logistic regression analysis of vitamin D levels for neonatal diseases

\begin{tabular}{lcc}
\hline \multirow{2}{*}{ Variable } & \multicolumn{2}{c}{ Vitamin $\mathrm{D}<20($ vs. vitamin $\mathrm{D} \geq 20)$} \\
\cline { 2 - 3 } & Adjusted $\mathrm{OR}^{*}(95 \% \mathrm{Cl})$ & $P$ value \\
\hline RDS & $4.32(1.80-10.38)$ & $\mathbf{0 . 0 1 0}$ \\
BPD & $4.11(1.11-15.23)$ & $\mathbf{0 . 0 3 5}$ \\
Pneumothorax & $3.19(0.14-74.39)$ & 0.471 \\
Pulmonary hemorrhage & $0.75(0.14-4.12)$ & 0.740 \\
PDA & $0.89(0.40-1.98)$ & 0.770 \\
ROP & $5.49(1.16-26.00)$ & 0.032 \\
NEC & $2.40(0.82-6.98)$ & 0.109 \\
Sepsis & $1.21(0.30-4.89)$ & 0.789 \\
PVL & $0.17(0.00-9.67)$ & 0.392 \\
IVH (grade III and IV) & $0.57(0.10-3.41)$ & 0.537 \\
\hline
\end{tabular}

$\mathrm{OR}$, odds ratio; $\mathrm{Cl}$, confidence interval; RDS, respiratory distress syndrome; BPD, bronchopulmonary dysplasia; PDA, patent ductus arteriosus; ROP, retinopathy of prematurity; NEC, necrotizing enterocolitis; PVL, periventricular leukomalacia; IVH, intraventricular hemorrhage; $\mathrm{OR}$, odds ratio; $\mathrm{Cl}$, confidence interval.

Boldface indicates a statistically significant difference with $P<0.05$.

*Logistic regression adjusted for the gestational age and vitamin D supplementation.

To evaluate the association between neonatal morbidities and vitamin D levels, we compared the rate of RDS among the 3 groups. There were 72 cases (86.7\%) of RDS in group 1, 45 cases (67.2\%) in group 2, and 16 cases (42.1\%) in group 3, a statistically significant difference $(P<0.001)$. Similarly, there was a higher rate of BPD in the lowest vitamin $\mathrm{D}$ group, and this difference was statistically significant $(P<0.001)$. RDS and BPD were more frequent in group 1 , although the percentage of surfactant usage was significantly higher in group 1.

In neonates with severe vitamin D deficiency, ROP was diagnosed more often $(P=0.001)$. There was no significant difference in the incidence of the following morbidities: pneumothorax, pulmonary hemorrhage, PDA, NEC, sepsis, PVL, and IVH (grades III and IV).

In Table 3, logistic regression analysis shows that vitamin D deficiency at birth was a risk factor for neonatal morbidities (RDS: odds ratio [OR], 4.32; $P=0.010$; BPD: $O R, 4.11 ; P=0.035$; and ROP: $\mathrm{OR}, 5.49 ; P=0.032$ ).

\section{Discussion}

Recently, several studies ${ }^{19-21)}$ have been reported on neonatal and maternal vitamin D deficiency in Korea. However, no studies have reviewed vitamin D deficiency in VLBWIs. In the present study, the average vitamin D level in 188 VLBWIs was $13.4 \pm 9.3 \mathrm{ng} / \mathrm{mL}$. In another Korean study, Shin et al. ${ }^{21)}$ observed that 668 newborns had an average 25(OH)D of $32 \mathrm{nmol} / \mathrm{L}$ (12.8 ng/mL). The present study shows that $79.8 \%$ of VLBWIs had vitamin D deficiency, and 44.1\% had severe vitamin D deficiency. According to Park et al., ${ }^{22)}$
91.7\% of preterm babies were vitamin $\mathrm{D}$ deficient $(\mathrm{n}=278$; from January 2013 to May 2015, mean gestational age of $33^{+5}$ weeks), and Ataseven et al. $^{8)}$ found that $97 \%$ of preterm babies were vitamin D deficient ( $n=190$; from October 2012 to June 2013, gestational age of 29-35 weeks). Similarly, according to Moon et al., ${ }^{20)} 97.4 \%$ of full-term babies were vitamin D deficient ( $n=122$; from March 2013 to December 2014, full term). Therefore, vitamin D deficiency affects a significant proportion of both full-term and preterm babies regardless of their gestational age.

In this study, the incidence of vitamin D deficiency is lower than past studies. It is supposed that this is due to differences in characteristics of the study population, such as birth weight, gestational age, and maternal vitamin $\mathrm{D}$ status.

The vitamin D level was higher in the summer and in the fall than in spring or winter in this study. According to Holick, ${ }^{23)}$ above $37^{\circ}$ latitude during the months from November through February, there are marked decreases ( 80\%-100\%) in the number of ultraviolet B photons reaching the earth's surface.

As in the study of Burris et al., ${ }^{14)}$ we could not prove any correlation between gestational age and vitamin D level. In this study, babies with a lower birth weight were vulnerable to vitamin $\mathrm{D}$ deficiency, which is in accordance with the study by Morgan et al. ${ }^{24)}$ They found an inverse association between 25(OH)D concentration and low birth weight.

Unlike our study, the Park et al. ${ }^{22)}$ study found that the risk of severe vitamin $\mathrm{D}$ deficiency in twin preterm infants was significantly higher than that in singletons (OR, 1.993; 95\% confidence interval, 1.137-3.494; $P=0.016)$.

The duration of oxygen usage, mechanical ventilation and noninvasive oxygen usage was longer in the lower vitamin D group. Kazzi et al. ${ }^{25)}$ scored RSS on the first day of life, and formed 3 categories: mild (1.0-3.9), moderate (4.0-6.9), and severe (7.0-10.0). Post hoc comparison with mean 25(OH)D levels demonstrated significant differences $(P=0.042)$. Also, the group with lower vitamin D levels had higher RSS $(P=0.012)$ on the first day of life, and a higher number of babies were treated with surfactant $(P=0.039)$.

In terms of respiratory morbidities, RDS was more frequent in preterm babies with severe vitamin D deficiency. Çetinkaya et al. ${ }^{9}{ }^{9}$ reported that vitamin D levels in patients with BPD were significantly lower in 132 preterm infants born at less than 32 weeks of gestation $(P<0.001)$, and all patients with BPD had vitamin D levels $<10$ $\mathrm{ng} / \mathrm{mL}$. It is not clear yet why babies with vitamin D deficiency are at higher risk for respiratory morbidities. However, we can hypothesize the cause and the consequences. Babies with vitamin $\mathrm{D}$ deficiency had a longer duration of $\mathrm{O}_{2}$ usage; therefore BPD would subsequently occur. ROP was also influenced by the duration of oxygen treatment. Therefore, it is assumed that ROP would also occur more in the group with the lowest vitamin D.

In Table 1, maternal age was significantly higher in the lower vitamin D group. There is no other research related to this result, and 
further analysis is needed. In addition, some studies have shown that low maternal vitamin D predisposes children to wheezing or asthma, ${ }^{26,27)}$ so the effect of vitamin D extends beyond the neonatal period to childhood and adolescence. Consequently, further studies are needed on the association between vitamin $\mathrm{D}$ and respiratory diseases.

The limitation of this study is that when we divided the patients into 3 groups, we did not correct for confounding factors (gestational age, birth weight, either twin or singleton, seasons of birth, maternal history, etc.). Moreover, we were unable to investigate the association between maternal serum vitamin D levels and fetal vitamin D levels because the data were not available. The World Health Organization/ Food and Agriculture Organization of the United Nations recommended that nutrient intake for vitamin $\mathrm{D}$ in pregnant women be $200 \mathrm{IU} / \mathrm{day}{ }^{28}{ }^{28}$ However, because of the limited evidence to directly assess the benefit and harm of vitamin $\mathrm{D}$ supplementation alone in pregnancy, the use of this intervention as part of routine antenatal care is also not recommended. ${ }^{29)}$ Nevertheless, as vitamin D deficiency is associated with preterm birth, ${ }^{30}$ small-for-gestational-age infants, ${ }^{31)}$ rickets, ${ }^{32)}$ preeclampsia, ${ }^{15)}$ and gestational DM, ${ }^{331}$ this picture is expected to improve with proper dosing. Another limitation is that this study may not be able to be generalized to other hospitals or other countries, as our study is a single-institutional study and the findings may vary according to nutritional status, race, sunlight exposure, and gestational age.

Vitamin D deficiency is a serious condition worldwide. According to the Korean National Health and Nutrition Examination Survey $2008{ }^{34)}$ vitamin D insufficiency was defined as $25(\mathrm{OH}) \mathrm{D}<20 \mathrm{ng} /$ $\mathrm{mL}$. The prevalence of vitamin D insufficiency was $47 \%$ in teenage boys and 64.5\% in teenage girls. Efforts to support adequate maternal vitamin D intake, outdoor activity during pregnancy, and an adequate supply of vitamin $\mathrm{D}$ in neonates are important for preventing neonatal respiratory morbidities. Further multicenter randomized trials and long-term follow up are needed to determine the effect of vitamin $D$ on respiratory outcomes.

\section{Conflict of Interest}

No potential conflict of interest relevant to this article was reported.

\section{Acknowledgments}

This work was supported by the Soonchunhyang University Research Fund.

\section{References}

1. Di Rosa M, Malaguarnera M, Nicoletti F, Malaguarnera L. Vitamin D3: a helpful immuno-modulator. Immunology 2011;134:123-39.

2. Fares S, Sethom MM, Khouaja-Mokrani C, Jabnoun S, Feki M, Kaabachi N. Vitamin A, E, and D deficiencies in tunisian very low birth weight neonates: prevalence and risk factors. Pediatr Neonatol 2014;55:196201.

3. Newhook LA, Sloka S, Grant M, Randell E, Kovacs CS, Twells LK. Vitamin D insufficiency common in newborns, children and pregnant women living in Newfoundland and Labrador, Canada. Matern Child Nutr 2009;5:186-91.

4. Sutherland ER, Goleva E, Jackson LP, Stevens AD, Leung DY. Vitamin $\mathrm{D}$ levels, lung function, and steroid response in adult asthma. Am J Respir Crit Care Med 2010;181:699-704.

5. Cetinkaya M, Cekmez F, Buyukkale G, Erener-Ercan T, Demir F, Tunc $\mathrm{T}$, et al. Lower vitamin D levels are associated with increased risk of early-onset neonatal sepsis in term infants. J Perinatol 2015;35:3945.

6. Gamal TS, Madiha AS, Hanan MK, Abdel-Azeem ME, Marian GS. Neonatal and maternal 25-OH vitamin D serum levels in neonates with early-onset sepsis. Children (Basel) 2017;4(5). pii: E37. https:// doi.org/10.3390/children4050037.

7. Cetinkaya M, Erener-Ercan T, Kalayci-Oral T, Babayiğit A, Cebeci B, Semerci SY, et al. Maternal/neonatal vitamin D deficiency: a new risk factor for necrotizing enterocolitis in preterm infants? J Perinatol 2017;37:673-8.

8. Ataseven F, Aygün C, Okuyucu A, Bedir A, Kücük Y, Kücüködük S. Is vitamin d deficiency a risk factor for respiratory distress syndrome? Int J Vitam Nutr Res 2013;83:232-7.

9. Çetinkaya M, Çekmez F, Erener-Ercan T, Buyukkale G, Demirhan A, Aydemir G, et al. Maternal/neonatal vitamin D deficiency: a risk factor for bronchopulmonary dysplasia in preterms? J Perinatol 2015; 35:813-7.

10. Joung KE, Burris HH, Van Marter LJ, McElrath TF, Michael Z, Tabatabai P, et al. Vitamin D and bronchopulmonary dysplasia in preterm infants. J Perinatol 2016;36:878-82.

11. Jobe AH. Animal models, learning lessons to prevent and treat neonatal chronic lung disease. Front Med (Lausanne) 2015;2:49.

12. Lemons JA, Bauer CR, Oh W, Korones SB, Papile LA, Stoll BJ, et al. Very low birth weight outcomes of the National Institute of Child health and human development neonatal research network, January 1995 through December 1996. NICHD Neonatal Research Network. Pediatrics 2001;107:E1.

13. Nguyen TM, Guillozo H, Marin L, Tordet C, Koite S, Garabedian M. Evidence for a vitamin D paracrine system regulating maturation of developing rat lung epithelium. Am J Physiol 1996;271(3 Pt 1):L3929.

14. Burris HH, Van Marter LJ, McElrath TF, Tabatabai P, Litonjua AA, Weiss ST, et al. Vitamin D status among preterm and full-term infants at birth. Pediatr Res 2014;75:75-80.

15. Wei SQ, Qi HP, Luo ZC, Fraser WD. Maternal vitamin D status and adverse pregnancy outcomes: a systematic review and meta-analysis. J Matern Fetal Neonatal Med 2013;26:889-99.

16. Bell MJ, Ternberg JL, Feigin RD, Keating JP, Marshall R, Barton L, et al. Neonatal necrotizing enterocolitis. Therapeutic decisions based upon clinical staging. Ann Surg 1978;187:1-7.

17. Fierson WM; American Academy of Pediatrics Section on Ophthalmology; American Academy of Ophthalmology; American Association for Pediatric Ophthalmology and Strabismus; American Association of Certified Orthoptists. Screening examination of premature 
infants for retinopathy of prematurity. Pediatrics 2013;131:189-95.

18. Holick MF, Binkley NC, Bischoff-Ferrari HA, Gordon CM, Hanley DA, Heaney RP, et al. Evaluation, treatment, and prevention of vitamin D deficiency: an Endocrine Society clinical practice guideline. J Clin Endocrinol Metab 2011;96:1911-30.

19. Cho SY, Park HK, Lee HJ. Efficacy and safety of early supplementation with $800 \mathrm{IU}$ of vitamin D in very preterm infants followed by underlying levels of vitamin D at birth. Ital J Pediatr 2017;43:45.

20. Moon JE, Lee JM, Ro DE, Kim HM. Vitamin D in Full-term neonates in Daegu and Gyeongbuk Province of Korea and the association with maternal and neonatal diseases. Korean J Perinatol 2015;26:329-35.

21. Shin YH, Yu J, Kim KW, Ahn K, Hong SA, Lee E, et al. Association between cord blood 25-hydroxyvitamin D concentrations and respiratory tract infections in the first 6 months of age in a Korean population: a birth cohort study (COCOA). Korean J Pediatr 2013;56:43945.

22. Park SH, Lee GM, Moon JE, Kim HM. Severe vitamin D deficiency in preterm infants: maternal and neonatal clinical features. Korean J Pediatr 2015;58:427-33.

23. Holick MF. Sunlight and vitamin D for bone health and prevention of autoimmune diseases, cancers, and cardiovascular disease. Am J Clin Nutr 2004;80(6 Suppl):1678S-1688S.

24. Morgan C, Dodds L, Langille DB, Weiler HA, Armson BA, Forest JC, et al. Cord blood vitamin D status and neonatal outcomes in a birth cohort in Quebec, Canada. Arch Gynecol Obstet 2016;293:731-8.

25. Kazzi SNJ, Karnati S, Puthuraya S, Thomas R. Vitamin D deficiency and respiratory morbidity among African American very low birth weight infants. Early Hum Dev 2018;119:19-24.

26. Bener A, Ehlayel MS, Tulic MK, Hamid Q. Vitamin D deficiency as a strong predictor of asthma in children. Int Arch Allergy Immunol 2012;157:168-75.

27. Kumar R. Prenatal factors and the development of asthma. Curr Opin Pediatr 2008;20:682-7.

28. World Health Organization. Guideline: vitamin D supplementation in pregnant women 2012. Geneva (Switzerland): World Health Organization, 2012.

29. De-Regil LM, Palacios C, Lombardo LK, Peña-Rosas JP. Vitamin D supplementation for women during pregnancy. Cochrane Database Syst Rev 2016;(1):CD008873.

30. Dawodu A, Nath R. High prevalence of moderately severe vitamin D deficiency in preterm infants. Pediatr Int 2011;53:207-10.

31. Leffelaar ER, Vrijkotte TG, van Eijsden M. Maternal early pregnancy vitamin D status in relation to fetal and neonatal growth: results of the multi-ethnic Amsterdam Born Children and their Development cohort. Br J Nutr 2010;104:108-17.

32. Greer FR. 25-Hydroxyvitamin D: functional outcomes in infants and young children. Am J Clin Nutr 2008;88:529S-533S.

33. Zhang C, Qiu C, Hu FB, David RM, van Dam RM, Bralley A, et al. Maternal plasma 25-hydroxyvitamin D concentrations and the risk for gestational diabetes mellitus. PLoS One 2008;3:e3753.

34. Choi HS, Oh HJ, Choi H, Choi WH, Kim JG, Kim KM, et al. Vitamin D insufficiency in Korea--a greater threat to younger generation: the Korea National Health and Nutrition Examination Survey (KNHANES) 2008. J Clin Endocrinol Metab 2011;96:643-51. 